اثر تاج تك درختان بنه (Pistacia atlantica Desf.) بر ميزان عناصر مغذى خاك جنكل (منطقه سروآباد استان كردستان)

يرستو رستمىزاد، وحيد حسينى" و كيومرث محمدى سمانى'

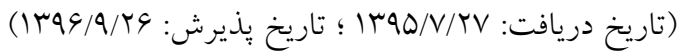

جكيده

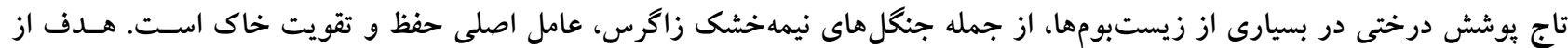

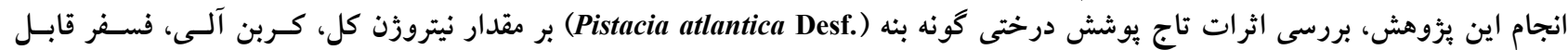

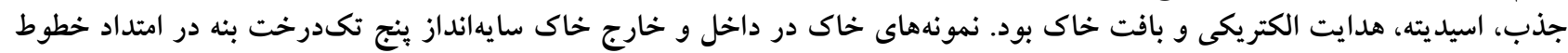

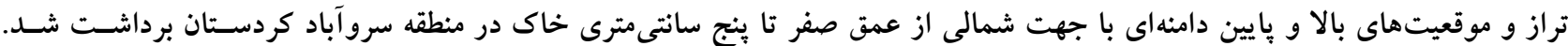

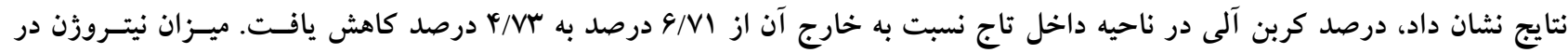

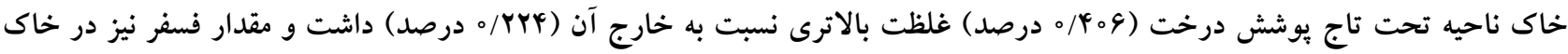

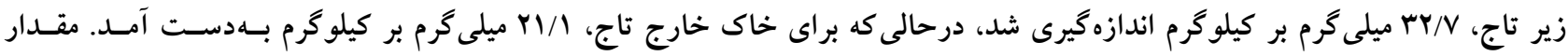

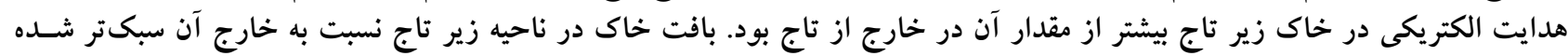

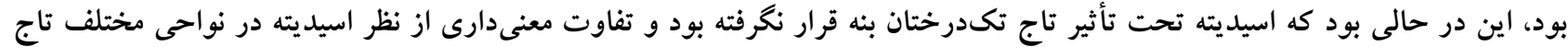

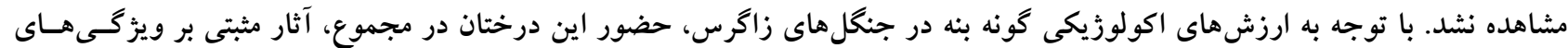

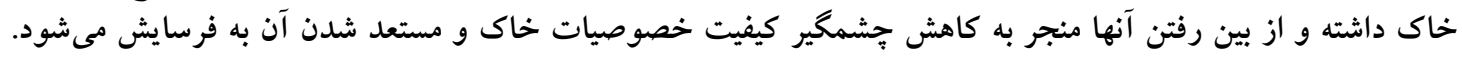

وازههاى كليدى: خصوصيات خاك، تاج بوشش درختى، زاگرس شمالى، بنه 
ميكروار كانيسمها (Yo) و همين طـور ترشـحات متفـاوتى كـه از

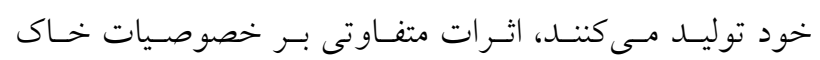

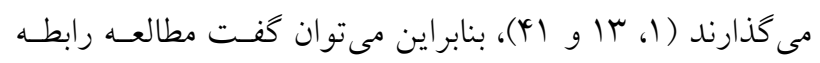

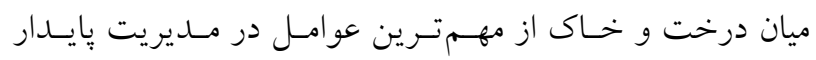

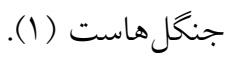

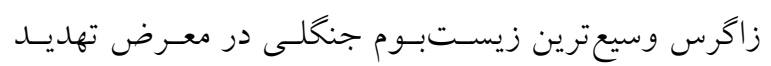

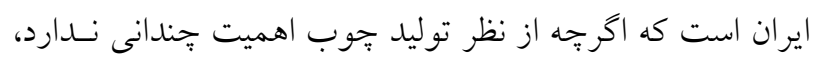

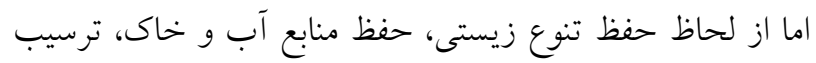

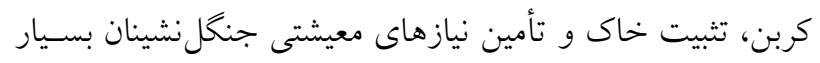

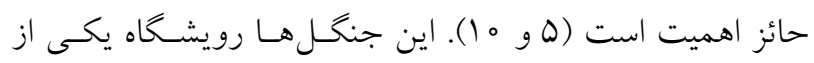
كونههاى درختى با ارزش به نام بنه (Pistacia atlantica Desf)

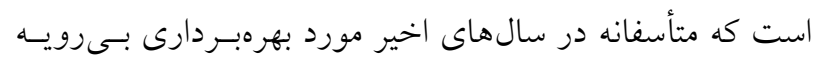

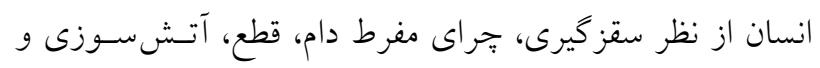

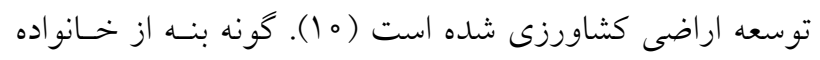

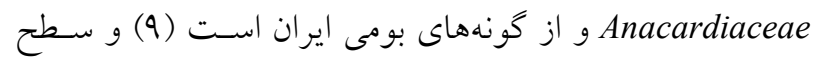

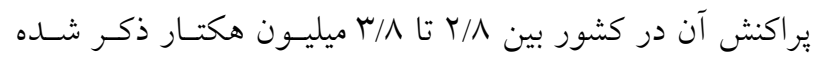

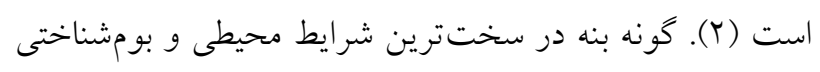

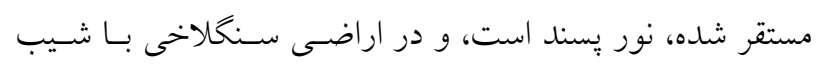

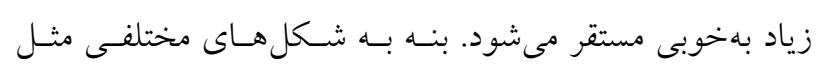

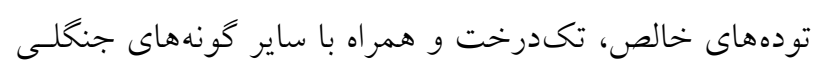

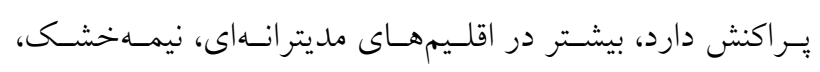

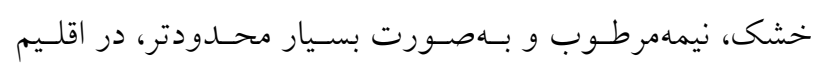

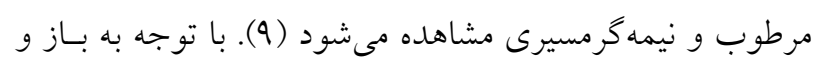

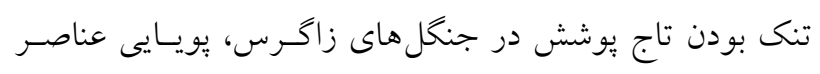

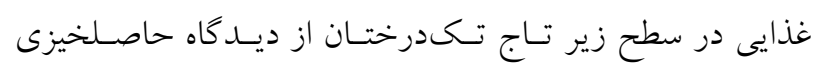

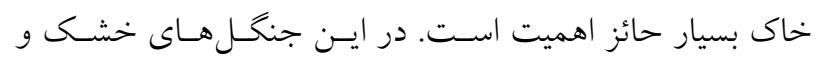

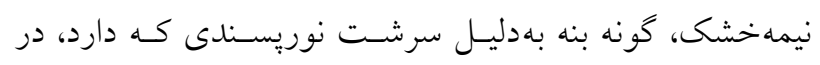

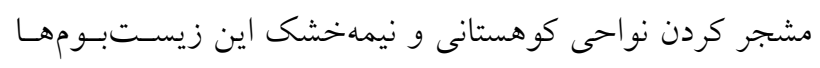

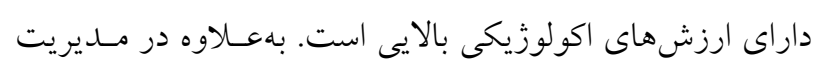

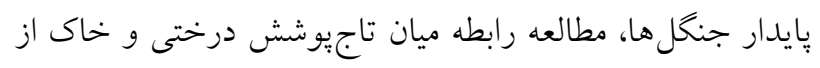

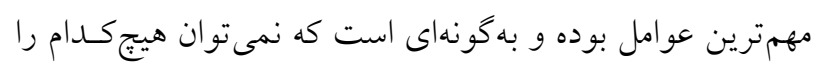

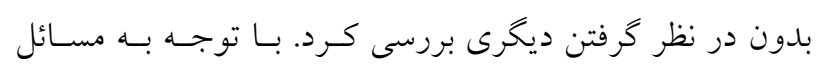

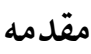

مطالعات زيادى اثرات مثبـت درختـان بــر حاصـلخيزى خـاك،

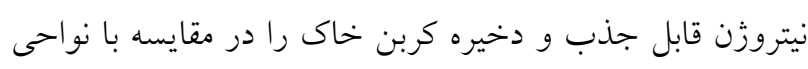

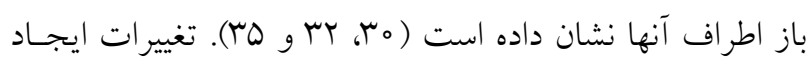

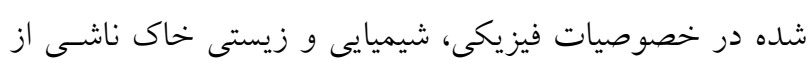

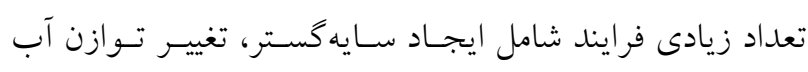

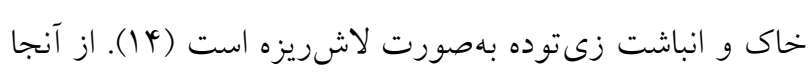

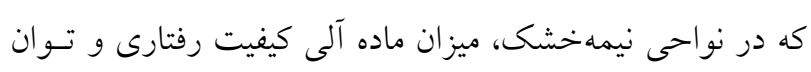

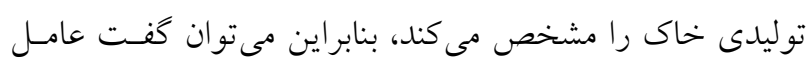

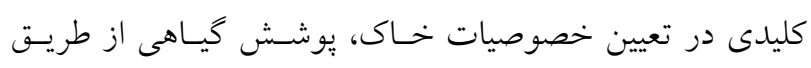

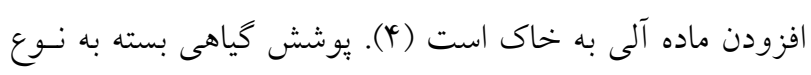
كونه بر خصوصيات خاك اثرات متفاوتى دارد، جرا كـه كياهـان

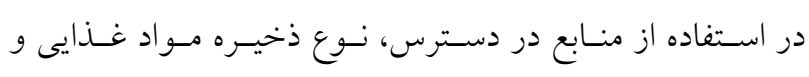

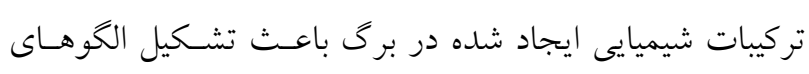

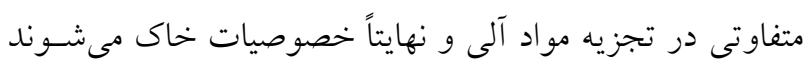
تك

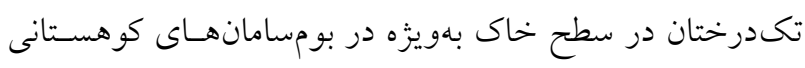

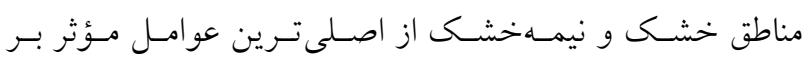

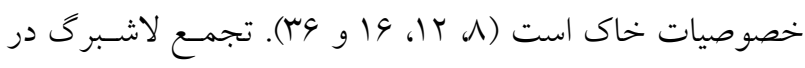
سطح زير تاج درخت موجب كاهش فشردگى، كاهش فرسايش

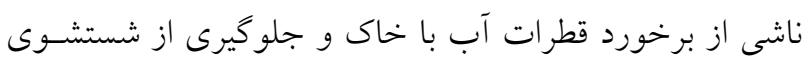

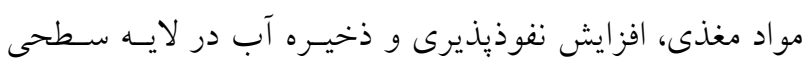
خاى مى شود (19)، ايسن خصوصسيات از منظـر توسعبه بايسـدار

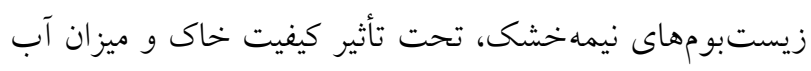

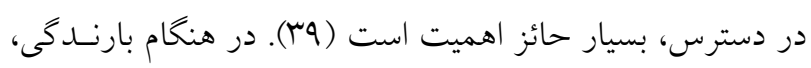

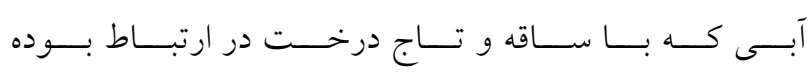

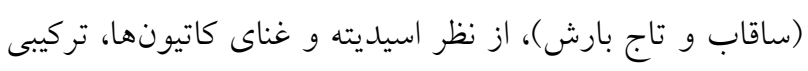

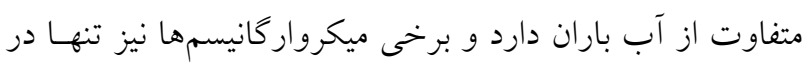

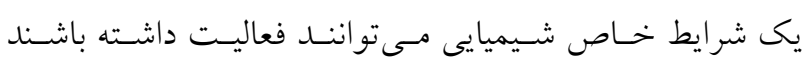
كه در حفظ حاصلخيزى خـاك امـرى مهـم اسـت (

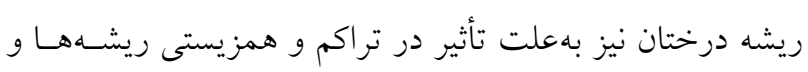

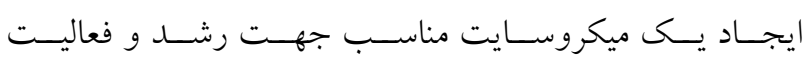




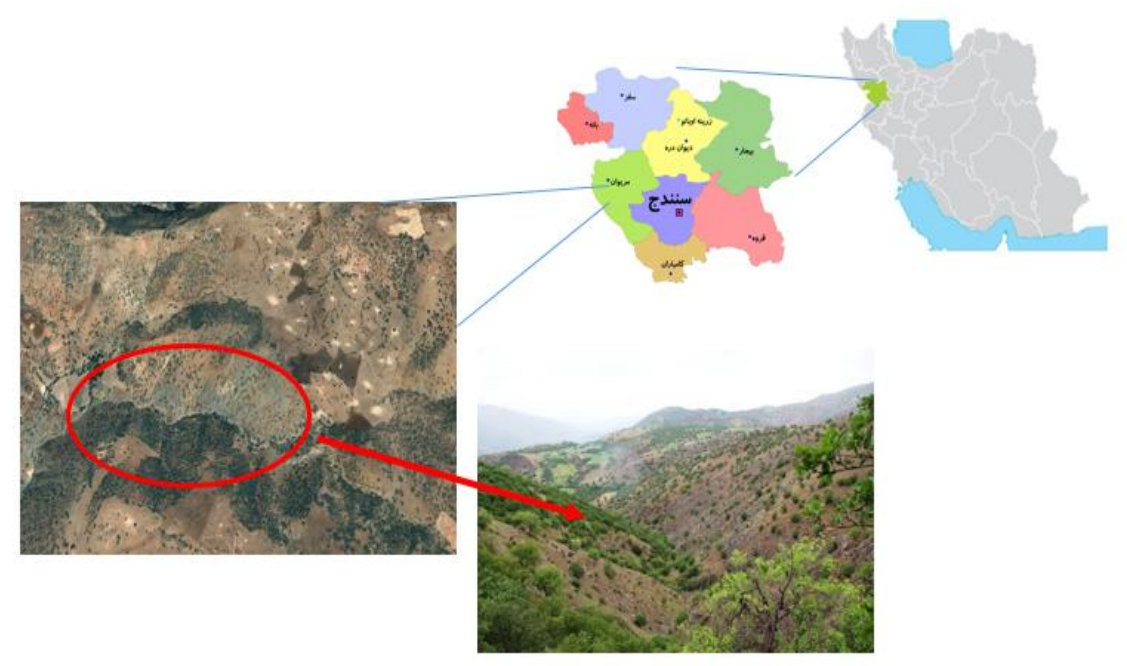

شكل ا. موقعيت جغر افيايى منطقه مورد مطالعه در كشور و استان كردستان

ترانسكت، نزديكترين درخت بنه انتخاب شد. سيس نمونههاى خاكى از عمق صفر تا بنج سانتى مترى خاك در زيـر تـاج و در

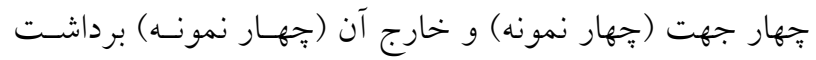

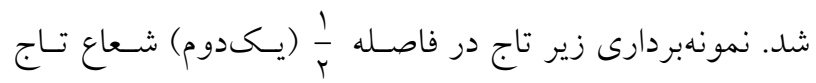
درخت تا تنه صورت كرفت، همجنــين بــراى نمونسهبـــدارى در بيرون تاج يوشش درخت، بههمان اندازه از قسمت انتهايى تـاج

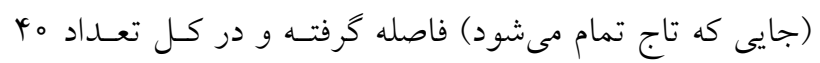
نمونه برداشت شد (شكل r). نمونههاى خاك يس از برداشـت بــه آزمايشـحاه انتقـال داده

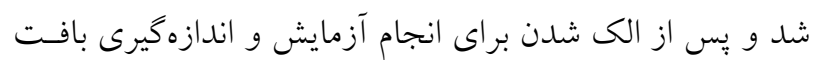

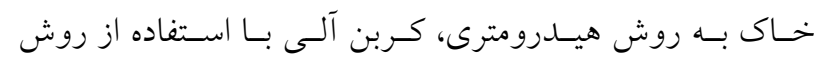
والكـى -بــلاك، نيتـروزن كـل از روش كجلــدال بــا دســـاه

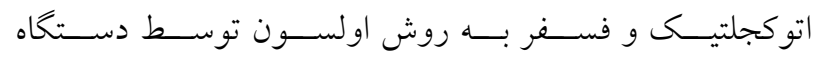

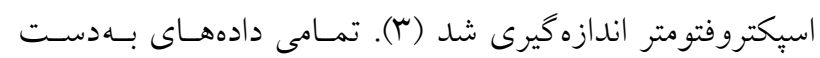

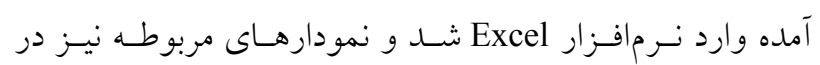
محيط همين نرمافزار رسم شد. دادهاى جمع آورى شـده ابتـدا با استفاده از آزمون كلموگروف-سميرونوف از نظر نرمال بـودن مورد بررسى قرار كرفتند، سيس با استفاده از آزمـون t مسـتقل، ميانگينهاى مختلف با همديخر مقايسه شـدند. بـراى تجزيسه و تحليل آمارى دادهها، از نرمافزار آمارى SPSS استفاده شد.
شرح داده شده و اهميت ويزه اين گونـه، هـدف از انجـام ايسن تحقيق بررسى و مقايسـه برخسى از خصوصسيات خـاك (بافـت

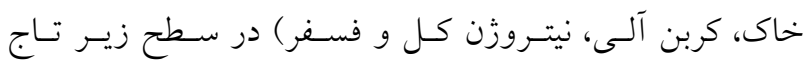
تكىدرختان بنه و خارج از آن روى دامنـهاى بـا جهـت شـمالى

\section{مواد و روشها} جنگل هاى اطراف شهر سروآباد بهدليل وجود تـكدرختـان بنـه بهعنوان محل اجراى تحقيق انتخاب شد (شكل (). معيـارى كـه با توجه به آن تكدرختان مورد نظر انتخـاب شـدند، قطـر تـاج تكدرختان بود كه داراى قطر تقريبى ^ تـا ها متـر بودنــ (Y). منطقه مورد مطالعه در طول \&4 درجه و 19 دقيقه تا \&4 درجه و

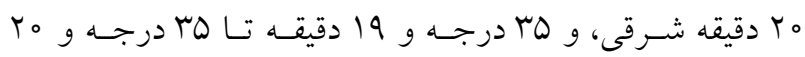
دقيقه عرض شـمالى قـرار دارد. وجــود كـوههـاى اورامانـات و شاهو، باعث تجمع رطوبت فراوان در شهرستان سروآباد شده و در نتيجه، موجب ايجاد يوشش جنگل در آن شده است (V).

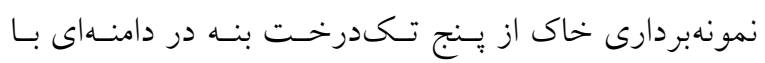
جهت شمالى و داراى شيب متوسط ها درصد صورت گرفـت. در ارتفاع همبا متر از سطح دريا، ترانسكتى به طول •Dr متر و عمود بر شيب دامنه بيـاده شـــ و بـه فاصسله مه متـر در طـول 


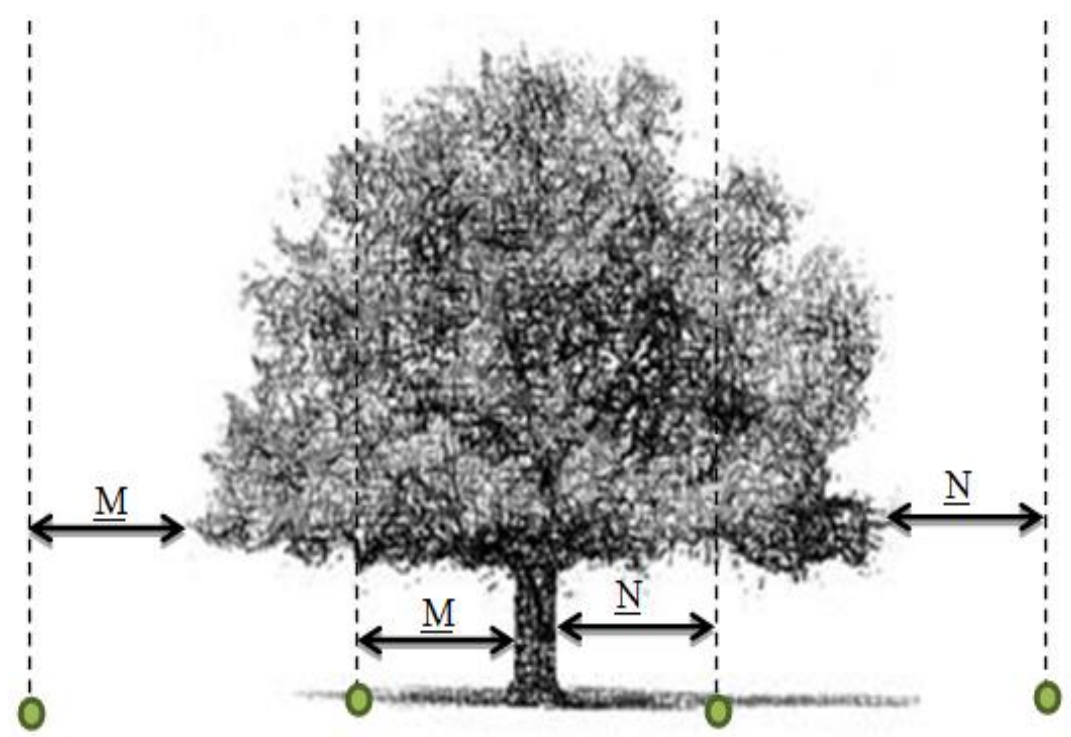

شكل r. شيوه نمونه بردارى از خاك تحت تاج تكدرختان بنه

ايجــاد ايسـن تفــاوت، بـهـ عــواملى جــون افـزودن لاشـبرى و

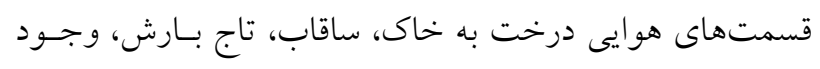

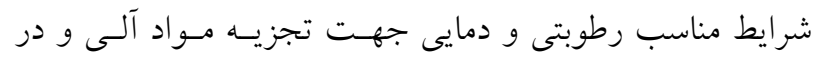

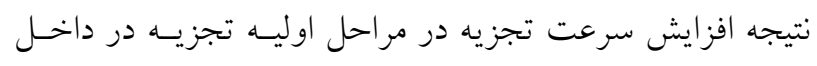

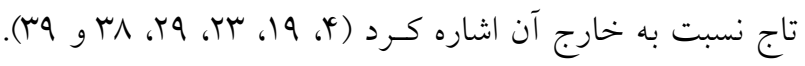

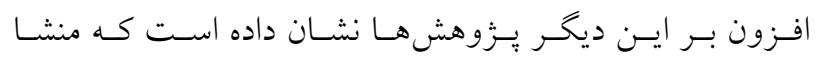

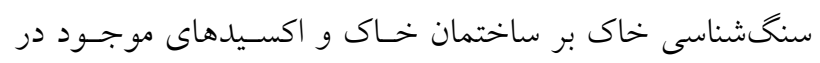

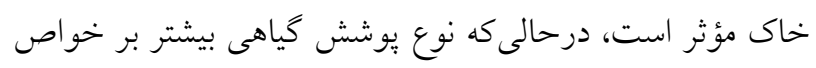

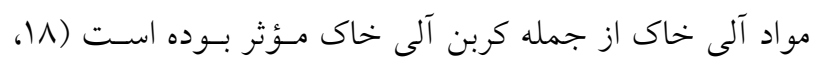
(r) (r)

طبق نتايج تحقيق حاضر، در نواحى زير تاج بوشش درخت،

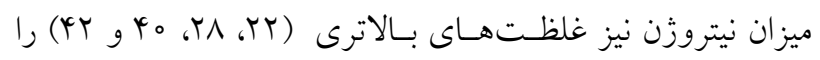

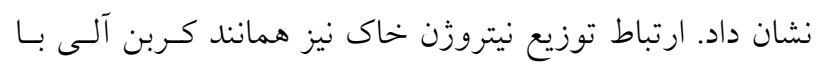

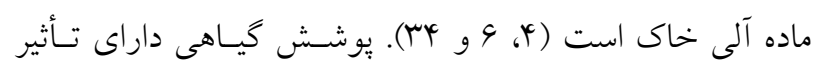

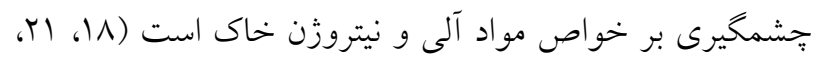

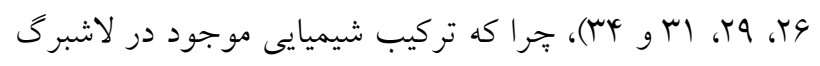

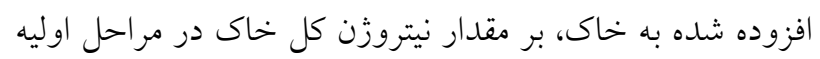

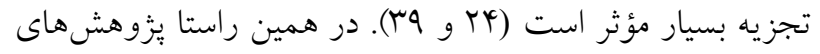

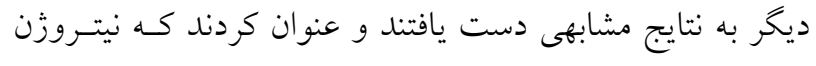
معـــنى (
نتايج و بحث در مقايسه ميزان عناصر كـربن، نيتـروزن و فسـفر خـاك در دو

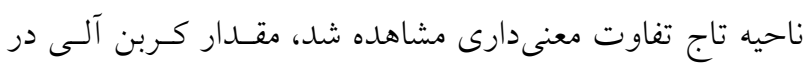

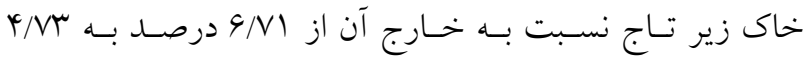
درصد كاهش يافت. تفاوت ميزان نيتـروزن در نـواحى مختلـف

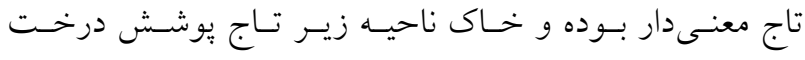

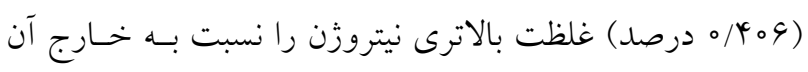

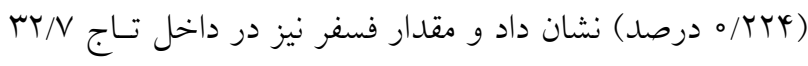

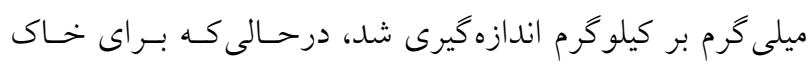

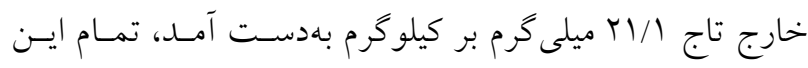

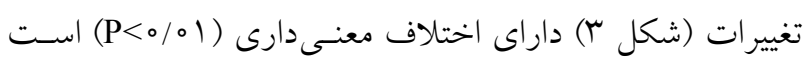

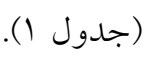

نتايج نشان داد كه بيشترين درصد كربن آلى در ناحيه زيـر

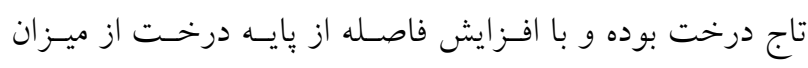

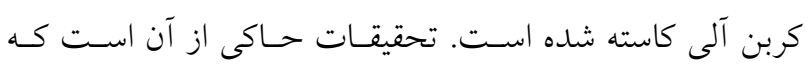

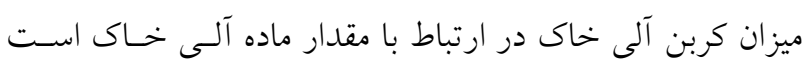

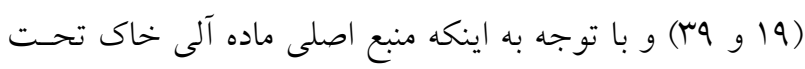

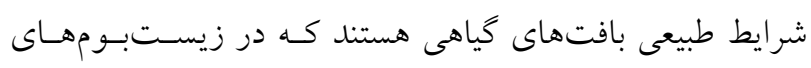

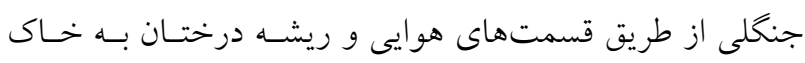

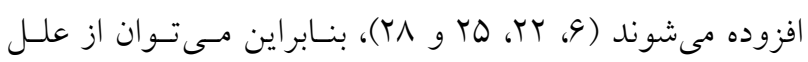



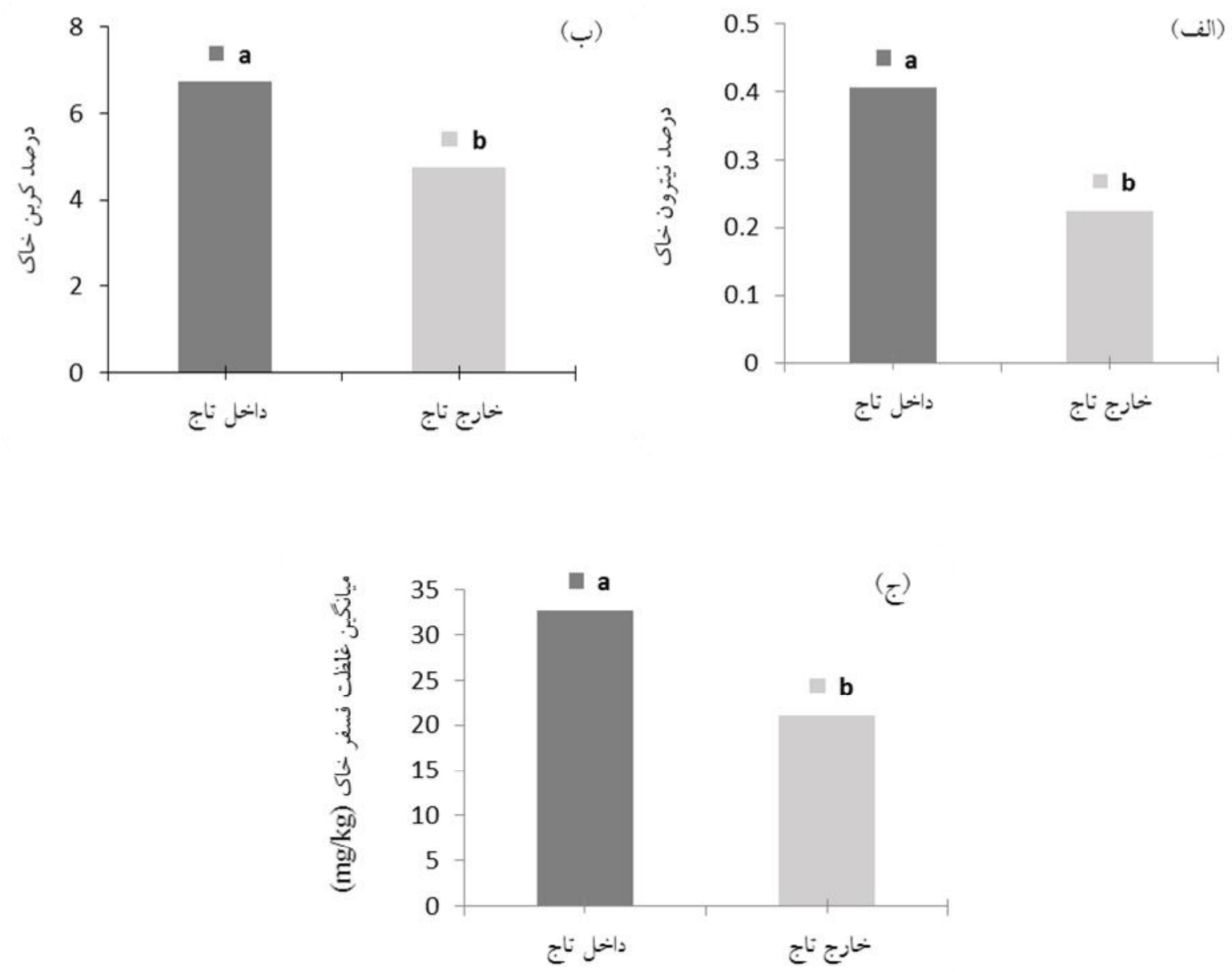

شكل r. نمودار وضعيت درصد كربن آلى، نيتروزن كل و فسفر قابل جذب الف) درصد نيتروزن كل، ب درصد كربن آلى و ج) فسفر قابل جذب در خاك زير و خارج تاج درخت. حروف انگليسى متفاوت بيانگر وجود تفاوت معنىدار بين دو موقعيت تاج درختان است

\begin{tabular}{|c|c|c|}
\hline \multicolumn{2}{|c|}{ مقايسه ميانكينها } & \multirow{2}{*}{ مشخصه كمى } \\
\hline $\mathrm{P}$ & Tحاسبه شده & \\
\hline $\mathrm{P}<0 / 01$ & $4 / 10$ & درصد كربن آلى \\
\hline $\mathrm{P}<0 / 01$ & $9 / \wedge V$ & درصد نيتروزن كل \\
\hline $\mathrm{P}<0 / 01$ & $r / 9 \Lambda$ & فسفر قابل جذب \\
\hline $\mathrm{P}<0 / 01$ & $Y / V \wedge$ & هدايت الكتريكى \\
\hline $\mathrm{P}>0 / \circ \mathrm{Q}$ &.$/ 9 \Lambda$ & اسيديته \\
\hline $\mathrm{P}<0 / 01$ & Y/AT & درصد رس \\
\hline $\mathrm{P}<0 / 01$ & $r / 9 \mu$ & درصد شن \\
\hline$P<0 / \circ D$ & $T / 09$ & درصد سيلت \\
\hline
\end{tabular}




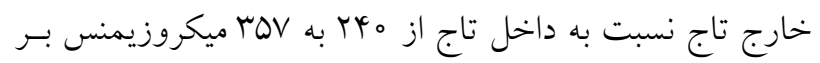

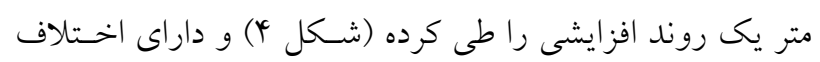

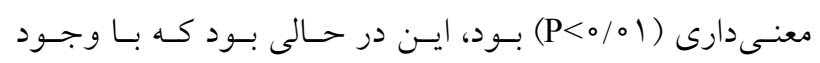

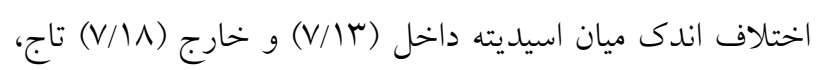

تفاوت معنى دارى بين اين دو ناحيه مشاهده نشد (جدول () ميدانه طبق نتايج حاصله از اين بررسى ميزان هدايت الكتريكى در

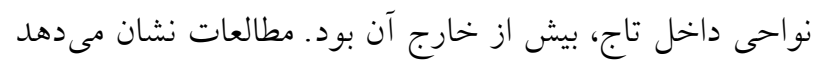

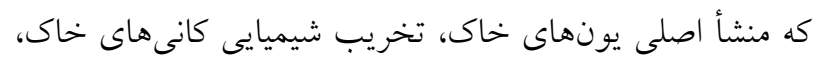

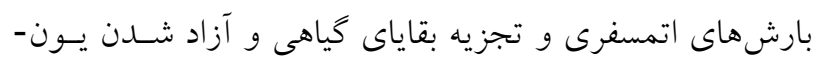

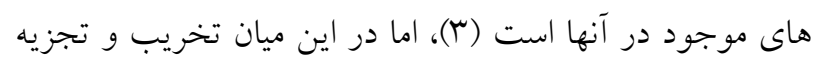

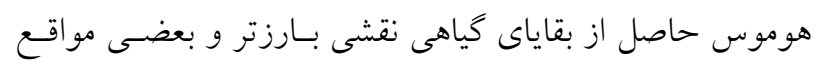

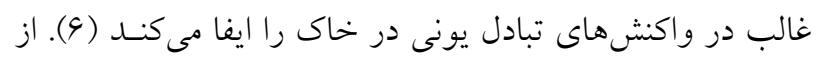

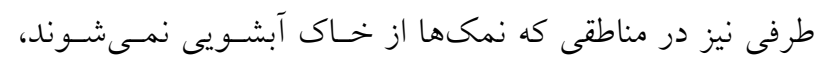

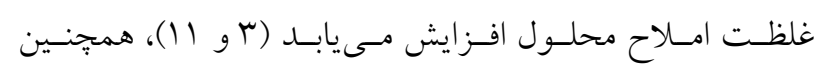

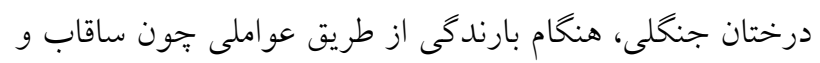

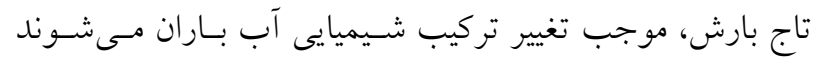

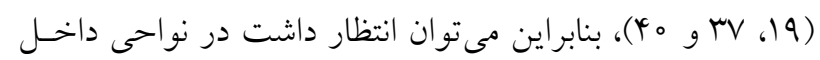
تاج بهدلايلى تجون وجود لاشبرى، رطوبت كـافى جهـت ايجـاد

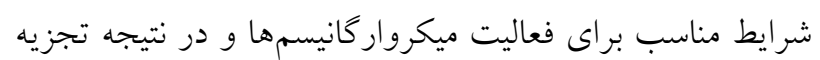

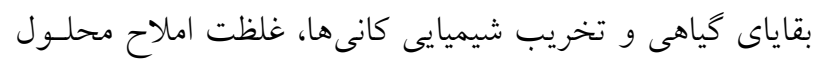

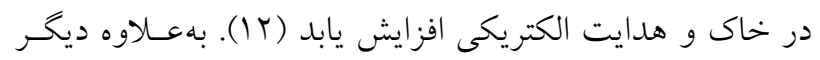

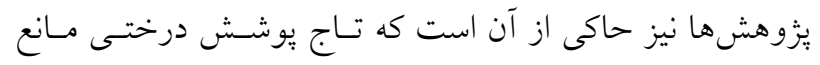

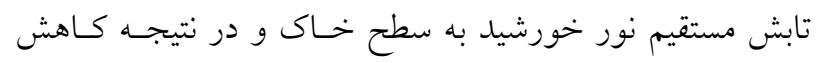

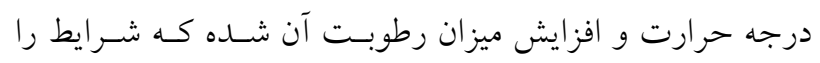

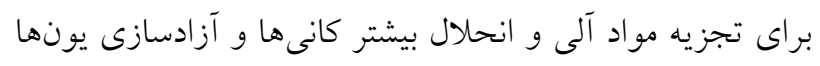

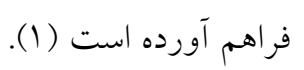

در بررسى اثرات تاج تكدرختان بنه با وجود تفاوت بسيار

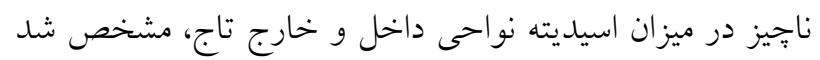
كه درخت بنه تأثيرى بر روى ميزان اسيديته خاك نداشته اسـتـ دئ. اين مطلب بهخوبى شناخته شده است كـه تفـاوت در تركيبـات

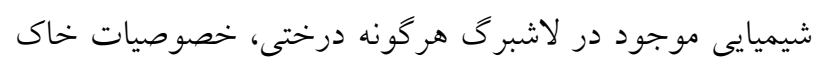

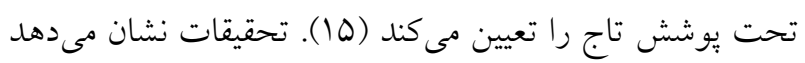

نواحى تحت تاج درخت بهدليل افزايش ماده آلى خـاك توسط

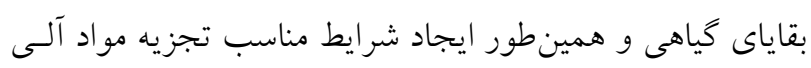

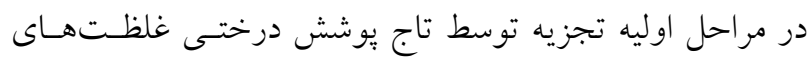

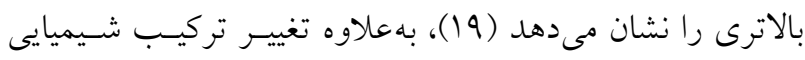

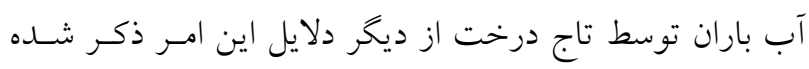

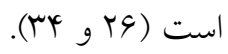
ميزان فسفر قابل جذب در ناحيه زير تاج درخت بنه بهطسور

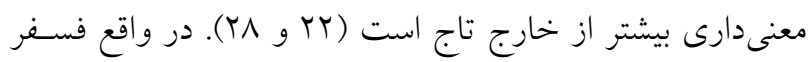

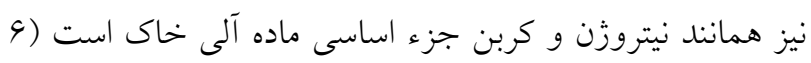

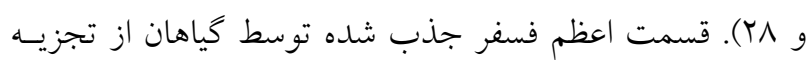

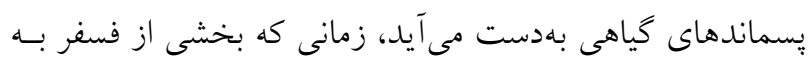

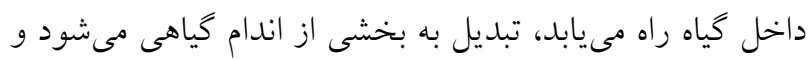

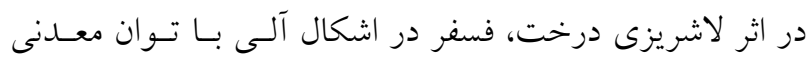

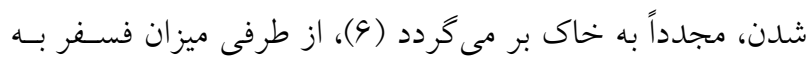

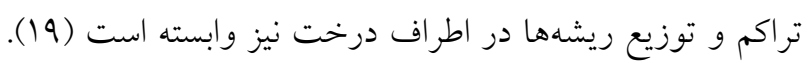

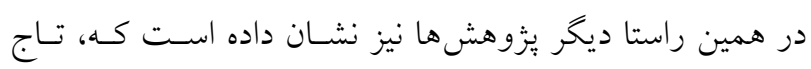

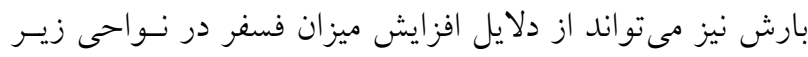

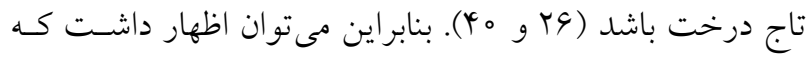

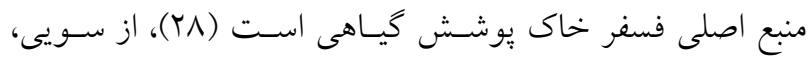

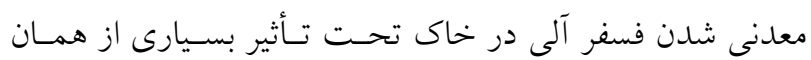
عوامل كه تجزيه عمومى ماده آلى خاك را كنترل مى كنند (دما و

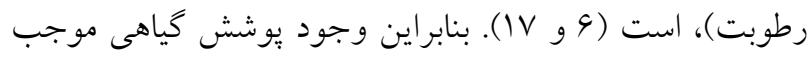

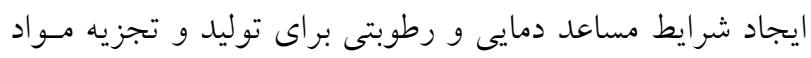

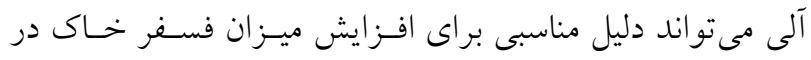

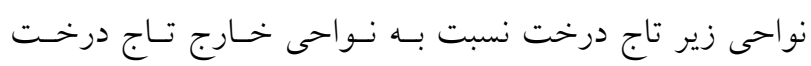

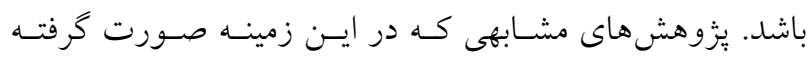

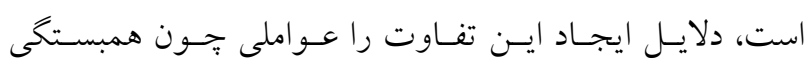

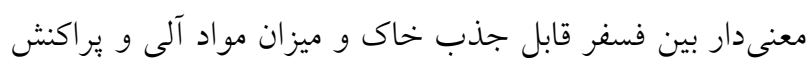

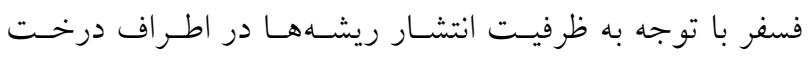

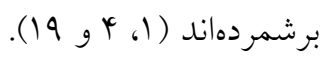

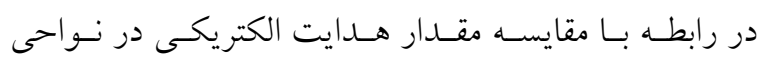

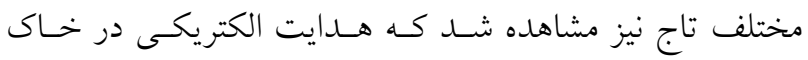




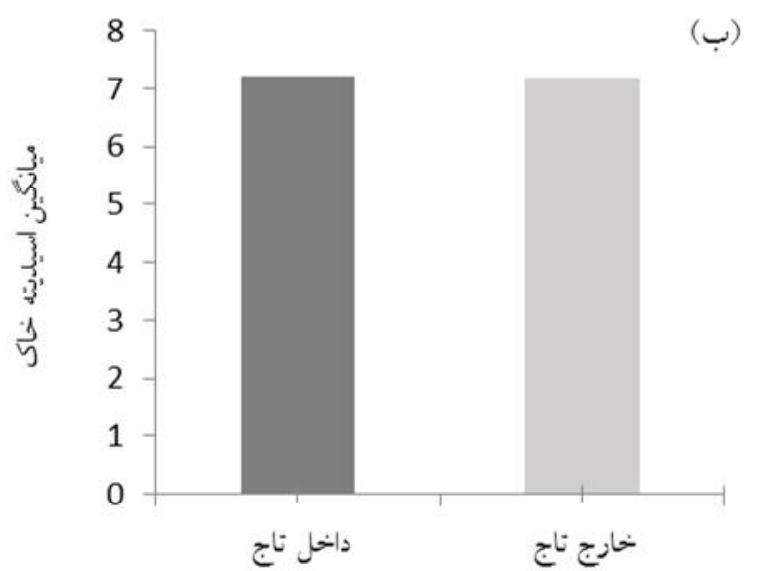

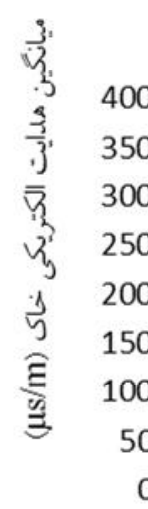

(الفـ)

شكل fا. نمودار وضعيت الف) مقدار هدايت الكتريكى و ب) اسيديته در خاك زير و خارج تاج درخت.

حروف انخليسى متفاوت بيانكر وجود تفاوت معنىدار بين دو موقعيت تاج درختان است

خاكى براى ناحيه خارج تاج از نوع رسى و بـراى ناحيـه داخـل

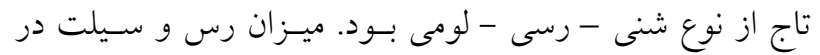
ناحيه خارج تاج و ميزان شن در ناحيه داخل تاج بيشترين مقدار را دارا بوده است كه بيشترين اختلاف بين تركيب ذرات تشكيل

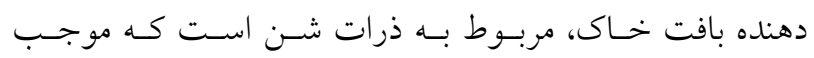

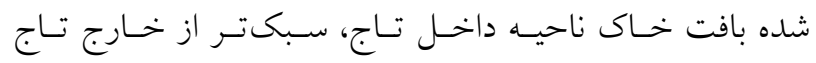

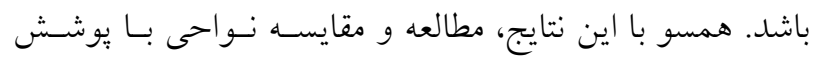

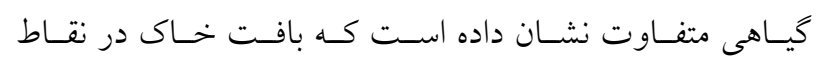

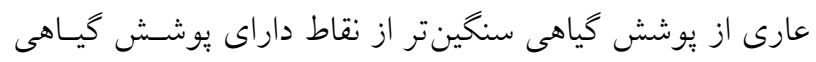

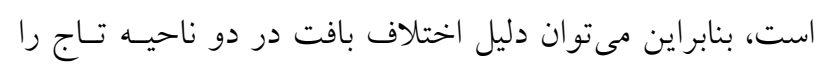

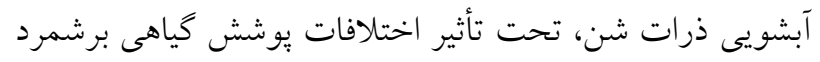

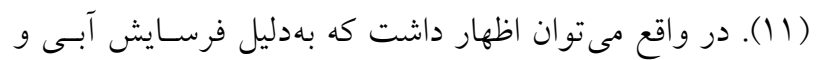

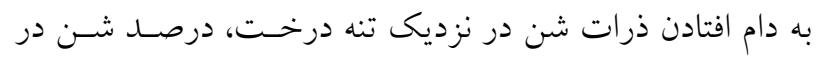
ناحيه سايهانداز درخت بيش از خارج آن بوده است (سب و و دَ).

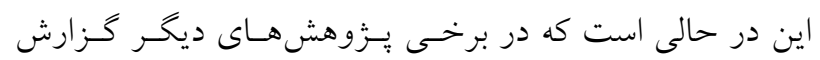

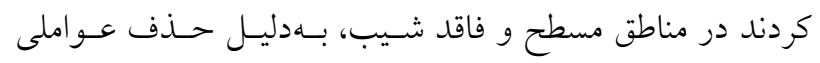

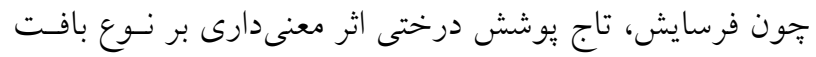

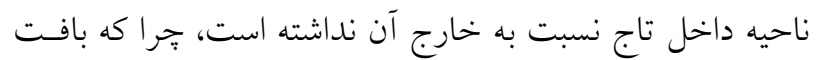
خـاك صـفتى بايــار اسـت و معمــولا از سـنخ مـادرى تـأثير

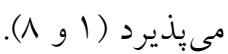

سقز و تربانتين موجود در تنه درخت بنه و اندامهاى مختلف آن حاوى مواد قليايى بوده، در اثر لاشريزى باييزه بـه خـاك اضـافه شده و موجب افزايش اسيديته خاك مى شود (N). از سوى ديكر مطالعات انجام كرفته بر روى بلوط حاكى از آن است كـه، ايـن درخت موجب كاهش معنىدار اسيديته در ناحيه زير تـاج خـود

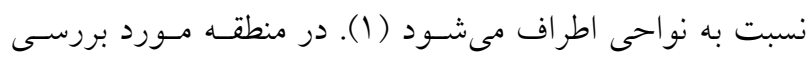

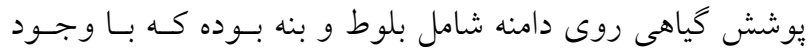

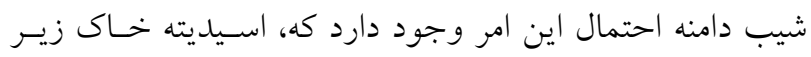

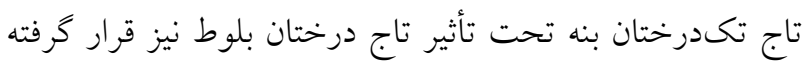

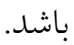
در خصوص بررسى اثر تاج درخت و مقايسه درصــ ذرات

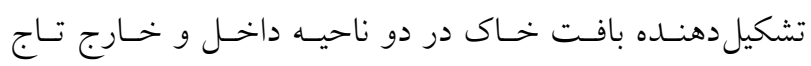
يوشش، مشخص شد كه درصد رس در خاك زير تاج نسبت به

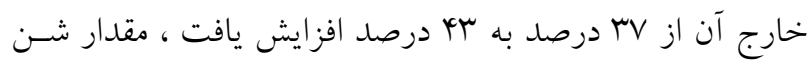

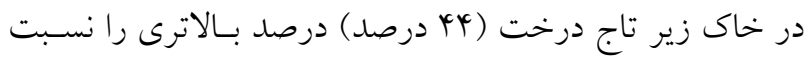

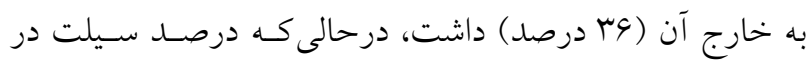
داخل تاج (19 درصد) بيشتر از خارج آن (الب درصد) بود، ايسن تغييرات (شكل ه) براى درصد ذرات شـن و رس (P<0/01) و

سيلت (P<0/0Q) داراى اختلاف معنى دارى است (جدول ()).

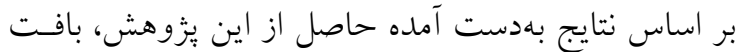



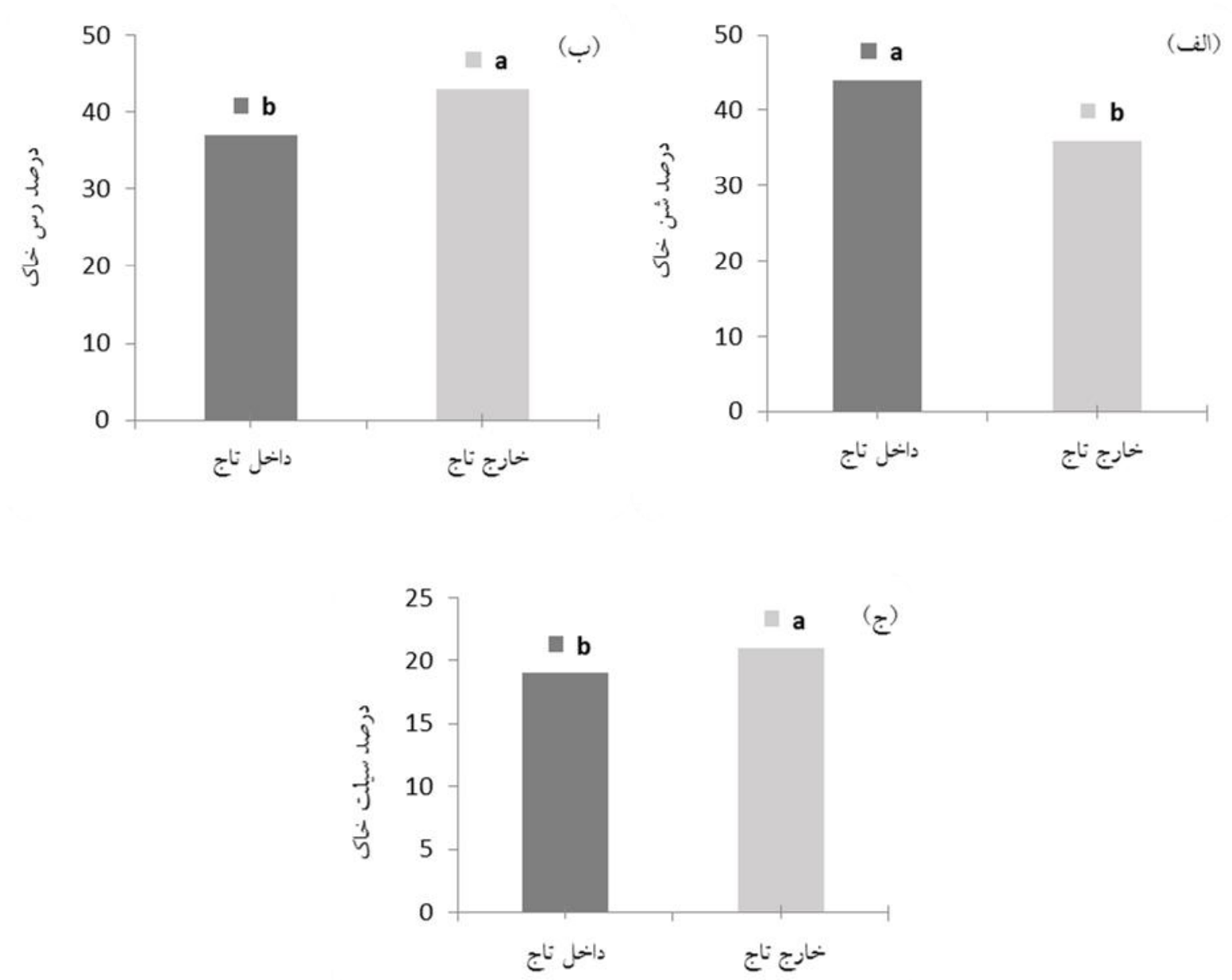

شكل ه. نمودار وضعيت درصد الف) شن ، ب) رس و ج) سيلت در خاك زير و خارج تاج درخت.

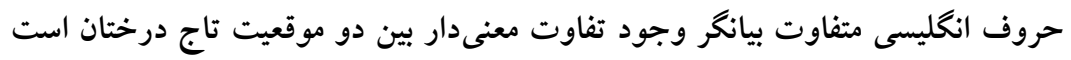

زير تاج و تجمع ذرات شن در اطراف تنه درخـت شــده اسـت. نتيجه گيرى

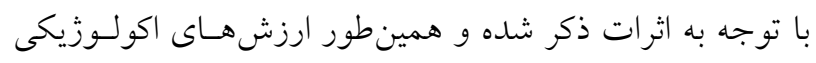

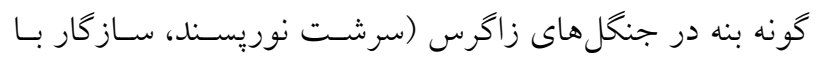

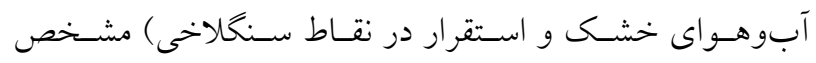

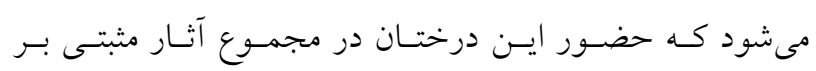

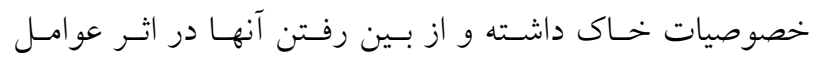

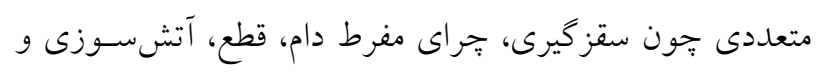

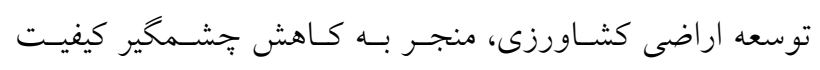

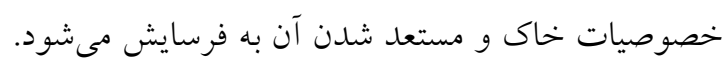
همانطور كه نتايج اين يزوهش نشان داد، درخت بنسه در بيشستر

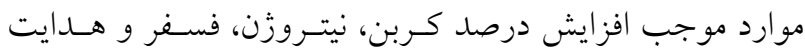

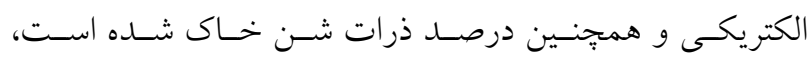

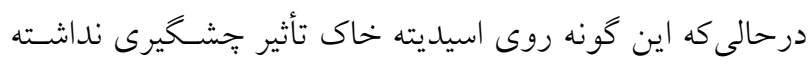

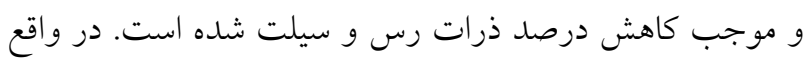

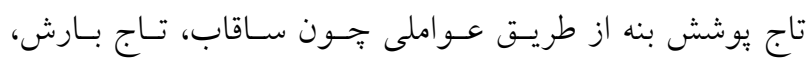

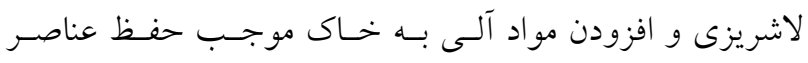

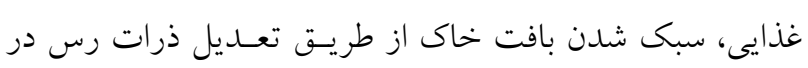


ا. اوليايى، ح.، ا. ادهمى، ه. فرجى و بٌ. فياض. •وبا. آثار درخت بلوط ايرانى بر برخى خصوصيات خاك در منطقه جنگلى ياسوج.

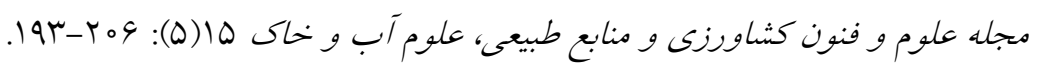

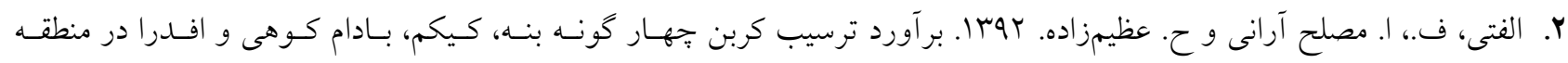

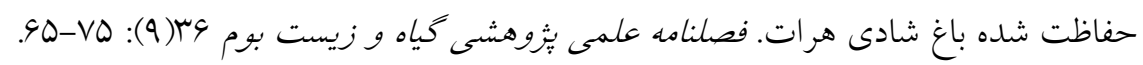

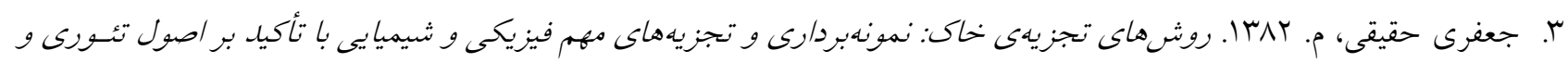

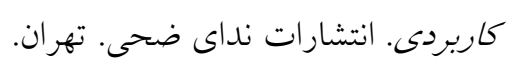

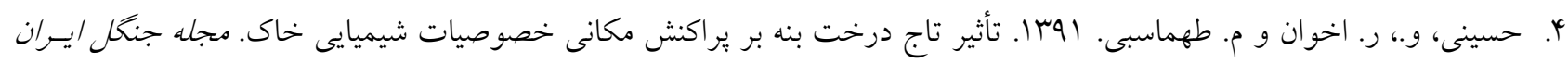
$.1 Y-r Y:(1) Y$

ه. حمزهيور، م.، س. بردبار، ل. جوكار و ع. عباسى. هیז|. بررسى امكان احياى جنگلهاى بنه از طريق كاشـت مسـتقيم بـذر و نهـال.

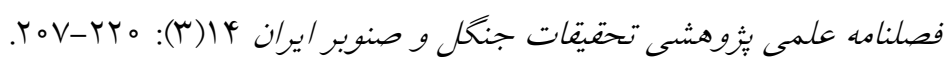
9. شاهويى، ص. هرץ ا. سرشت و خصوصيات خاكها (ترجمه). انتشارات دانشخاه كردستان. كردستان.

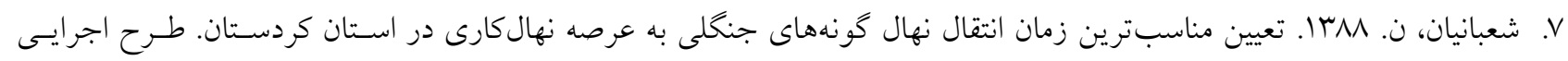
مركز تحقيقات كشاورزى و منابع طبيعى استان كردستان. كردستان.

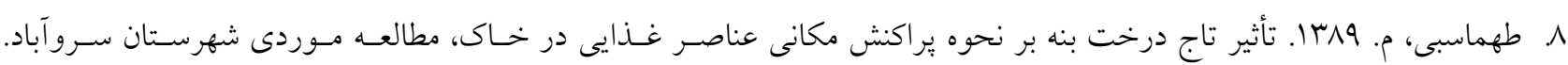
وياياننامه كارشناسى ارشد جنخلدارى، دانشكده منابع طبيعى، دانشخاه كردستان.

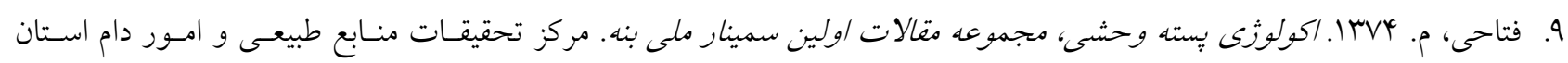
ايلام، وزارت جاد سازندگى، معاونت آموزش و تحقيقات. ايلام.

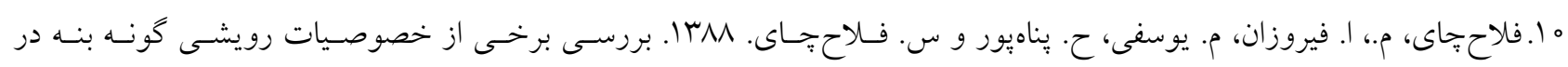

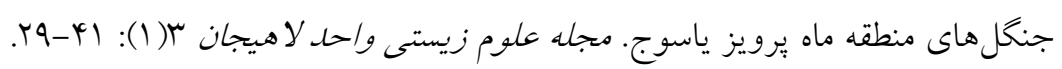

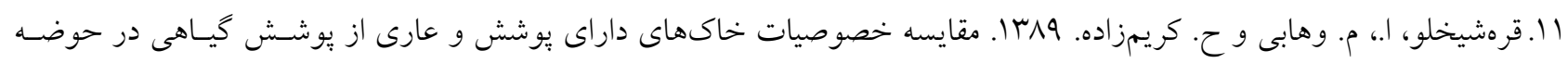

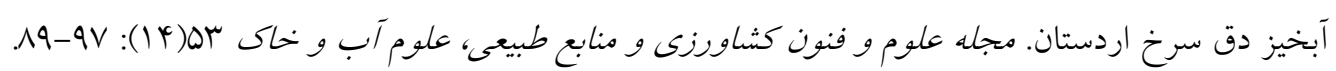

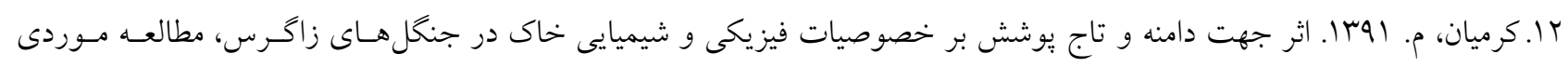

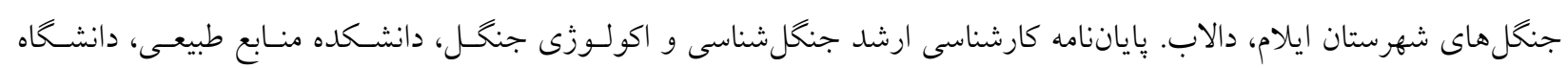
كردستان. كردستان.

سا. هاشمى، س.، س. حجتى و س. حسينى نصر. اqجا. بررسى خصوصيات شميايى خاك، مقدار لاشريزى و ورود عناصر غـذايى در

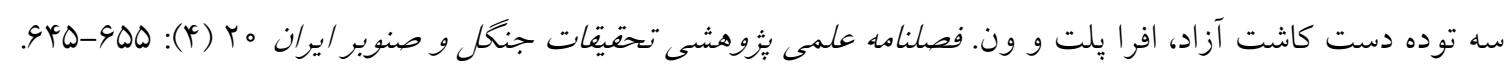

14. Becker, J. N., A. Gutlein, N. S. Cornejo, R. Kiese, D. Hetrel and Y. Kuzyakov. 2017. Legume and Non-legume Trees Increase Soil Carbon Sequestration in Savanna. Ecosystems 20(5): 989-999.

15. Beniamino, F., J. F. Ponge and P. ArPin. 1991. Soil acidification under the crown of oak trees I. Spatial distribution. Forest Ecology and Management 40(3): 221-232.

16. Charley, J. L. and N. E. West. 1977. Micro-Patterns of nitrogen mineralization activity in soils of some shrubdominated semi-desert ecosystems of Utah. Soil Biology and Biochemistry 9(5): 357-365.

17. Coble, D. W., K. S. Milner and J. D. Marshall. 2001. Above- and below-ground Production of trees and other vegetation on contrasting asPects in western Montana: a case study. Forest Ecology and Management 142(1-3): 231-241. 
18. Dahlgren, R. A., J. L. Boettinger, G. L. Huntington and R. G. Amundson. 1997 Soil develoPment along an elevational transect in the western Sierra Nevada, California. Geoderma 78(3): 207-236.

19. Gallardo, A. 2003. Effect of tree canoPy on the sPatial distribution of soil nutrients in a Mediterranean Dehesa. Pedobiologia 47(2): 117-125.

20. Hertel, D. 2011. Tree roots in canoPy soils of old EuroPean beech trees-An ecological reassessment of a forgotten Phenomenon. Pedobiologia 54(2): 119-125.

21. Jackson, L. E., R. B. Strauss, M. K. Firestone and J. W. Bartolome. 1990. Influence of tree canoPies on grassland Productivity and nitrogen dynamics in deciduous oak savanna. Agriculture, Ecosystems and Environment 32(1): 89105.

22. Klemmedson, J. O. 1991. Oak influence on nutrient availability in pine forests of central Arizona. Soil Science Society of America Journal 55: 248-253.

23. Ko, L. J. 1993. Oak tree effects on soil and herbaceous vegetation in savannas and Pastures in Wisconsin. American Midland Naturalist 130: 31-42.

24. Kobal, M., H. Grčman, M. ZuPan, T. Levanic, P. Simoncic, A. Kadunc and D. Hladnik. 2015 Influence of soil ProPerties on silver fir (Abies alba Mill.) growth in the Dinaric Mountains. Forest Ecology and Management 337: 77-87.

25. Labaz, B., B. Galka., A. Bogacz, J. Waroszewski and C. Kabala. 2014 Factors influencing humus forms and forest litter ProPerties in the mid-mountains under temPerate climate of southwestern Poland. Geoderma 230-231: 265273.

26. Lovett, G. M. and S. E. Lindberg. 1993. Atmospheric deposition and canopy interactions of nitrogen in forests. Canadian Journal of Forest Research 23(8): 1603-1616.

27. Miles, J. 1985. The Pedogenic effects of different sPecies and vegetation types and the implications of succession. Journal of Soil Science 36(4): 571-584.

28. Moreno, G., J. J. Obrador and A. García. 2007. Impact of evergreen oaks on soil fertility and crop production in intercropped dehesas. Agriculture, Ecosystems and Environment 119(3-4): 270-280.

29. Moughalu, J. I. and H. O. Awokunle. 1994. Spatial patterns of soil properties under tree canopy in nigerian rain forest region. Tropical Ecology 35: 219-228.

30. Otieno, D., J. Ondier, S. Arnhold, D. Okach, M. Ruidisch, B. Lee, A. Kolb, J. Onyango and B. Huwe. 2015. Patterns of $\mathrm{CO}_{2}$ exchange and productivity of the herbaceous vegetation and trees in a humid savanna in western Kenya. Plant Ecology 216: 1441-56.

31. Oyonarte, C., V. Aranda and P. Durante. 2008. Soil surface properties in Mediterranean mountain ecosystems: Effects of environmental factors and implications of management. Forest Ecology and Management 254(2): 156165.

32. Perakis, S. S. and C. H. Kellogg. 2007. Imprint of oaks on nitrogen availability and d15N in California grasslandsavanna. A case of enhanced N inputs. Plant Ecology 191: 209-220.

33. Perkins, S. R., K. C. McDaniel and A. L. Ulery. 2006 Vegetation and soil change following creosotebush Larrea tridentata control in the chihuahuan desert. Journal of Arid Environments 64(1): 152-173.

34. Petersen, A., N. Larson and D. Neufeld. 2002. Quercus Macrocarpa Has No Significant Effect on Surrounding Soil in Restored Savannas. Biology Department, Grinnell College, Grinnell, IA50112, USA.

35. Rascher K. G., C. Hellmann, C. Maguas and C. Werner. 2012. Community scale 15 N isoscapes: tracing the spatial impact of an exotic N2 -fixing invader. Ecology Letters 15: 484-91.

36. Rhoades, C. C. 1996. Single-tree influences on soil properties in agroforestry: lessons from natural forest and savanna ecosystems. Agroforestry Systems 35(1): 71-94.

37. Rossetti, I., S. Bagella, C. CaPPai, M. C. Caria, R. Lai, P. P. Roggero, P. Martins da Silva, J. P. Sousa, P. Querner and G. Seddaiu. 2015. Isolated cork oak trees affect soil properties and biodiversity in a Mediterranean wooded grassland. Agriculture, Ecosystems and Environment 202: 203-216.

38. Sebastià, M. T., E. Marks and R. M. Poch. 2008. Soil carbon and plant diversity distribution at the farm level in the savannah region of Northern Togo (West Africa). Biogeosciences Discussions 208: 4107-4127.

39. Shukla, M. K., R. Lal, M. Ebinger and C. Meyer. 2006. Physical and chemical properties of soils under some pinonjuniper-oak canopies in a semi-arid ecosystem in New Mexico. Journal of Arid Environments 66(4): 673-685.

40. Sollins, P., C. C. Grier, F. M. Crison, K. J. R. Cromack, R. Fogel and R. L. Fredriksen. 1980. The international element cycles of an old-growth Douglad-fir ecosystem in western Oregon. Ecological Monographs 50: 261-285.

41. Wilson, B. 2002. Influence of scattered paddock trees on surface soil properties: A study of the Northern Tablelands of NSW. Ecological Management and Restoration 3(3): 211-219.

42. Zheng, J., M. He, X. Li, Y. Chen, X. Li and L. Liu. 2008. Effects of Salsola passerina shrub patches on the microscale heterogeneity of soil in a montane grassland, China. Journal of Arid Environments 72(3): 150-161. 


\title{
The Effects of Persian Turpentine (Pistacia atlantica Desf) Single-trees Crown on the Amount of Nutrients in the Forest Soil (Sarvabad Region in Kurdistan Province)
}

\author{
P. Rostamizad, V. Hosseini ${ }^{*}$ and K. Mohammadi samani ${ }^{1}$
}

(Received: October 18-2016; Accepted: December 17-2017)

\begin{abstract}
Trees crown can be regarded as main factor contributing to the conservation and support of soil in many ecosystems including semiarid forests in Zagross. The aim of this study was to find out the effect of tree crown of pictachio (Pistacia atlantica Desf) on N, OC, P, pH, EC and the texture of the soil. Soil samples were collected in and outside the crown of 5 single pistachio trees on four directions of each tree in a northern slope from the $0-5 \mathrm{~cm}$ depth of soil in the Sarvabad region, Kurdistan. The results of this study showed that the amount of the soil organic carbon was decreased from $6.71 \%$ in the soil inside tree crowns to $4.73 \%$ in the soils outside the tree canopies. The soil inside trees had a higher concentration of soil nitrogen $(0.406 \%)$ than the one outside $(0.224 \%)$ the tree crown; the concentration of phosphorus was measured to be $32.7 \mathrm{mg} / \mathrm{kg}$ in the soil inside canopy, while it was $21.1 \mathrm{mg} / \mathrm{kg}$ in the soil of outside the tree canopy. EC under the tree crowns was more than that outside the canopy. The results, therefore, showed that soil texture was lighter inside the canopy, as compared to outside; however, the acidity of the soil was not affected by tree crowns and no significant differences were observed in different areas of the crown. Therefore, Persian turpentine trees have positive impacts on the soil properties in Zagros forests and eliminating them will lead to the significant loss of soil fertility and greater soil erosion.
\end{abstract}

Keywords: Soil properties, Tree canopy, Northern Zagross, Pistachio

1. Department of Forestry, Faculty of Natural Resources, University of Kurdistan, Kurdistan, Iran.

*: Corresponding Author, Email: v.hosseini@uok.ac.ir 